\title{
Effect of selected yogic practice and bench step aerobics on improving selected physiological variables of females at Wollega University, Ethiopia: Randomized comparative
} trial

\author{
Edosa Jabesa ${ }^{1}$, Medhanit Belay ${ }^{1}$ and Ginenus Fekadu ${ }^{2 *}$ \\ ${ }^{1}$ Department of Sport Studies, College of Computational and Natural Sciences, Wollega University, Nekemte, Ethiopia \\ ${ }^{2}$ Department of Pharmacy, Institute of Health Sciences, Wollega University, Nekemte, Ethiopia
}

\begin{abstract}
Background: Yoga is ultimate for developing harmony among body, mind and spirit. The purpose of this study was to investigate the effect of selected yogic practice and bench step aerobics training on improving selected physiological variables of females at Wollega University.

Method: Sixty female students were divided into three equal groups on random basis (groups I, II, and III) consisting of 20 study participants in each group. Two out of the three groups were given experimental treatments: yogic practice (group- I), bench step aerobics (group- II) while the remaining one group (group- III) was designated as control group. The study was formulated as completely randomized comparative trial, consisting of a pre-test and post-test. The collected data from the three group's pretest and posttest were statistically analyzed using analysis of covariance (ANCOVA). The Least significant difference (LSD) post hoc test was applied to determine significant differences among paired mean values. The $95 \%$ level of confidence was used and p-value $<0.05$ was considered as statistically significant.

Results: The findings of the study on physiological variables revealed that yogic practice (YP) group and bench step aerobics (BSAE) group showed significant superiority over the control group in reducing respiratory rate $(\mathrm{p}<0.05)$. The mean change made by the two experimental groups ( $\mathrm{p}>0.05)$ didn't show statistically significant difference. The finding also revealed that YP group and BSAE group significantly improved breath holding time than control group ( $>0.05$ ). The mean change made by the two experimental groups $(\mathrm{p}<0.05)$ didn't show statistically significant difference. BSAE training was found to be significantly better in decreasing resting heart rate of the study participants than YP group (Mean difference $\left.(\mathrm{MD})=2.18^{*}, \mathrm{p}<0.05\right)$.

Conclusion: The experimental groups; selected yogic practice groups (YPG) and bench step aerobics training (BSAEG) had significantly improved the selected physiological variables in contrast to control group. BSAE training was found to be significantly better on improving resting heart rate than yogic practice group and control group.
\end{abstract}

Abbreviations: YPG: Yoga practice group; BSAEG: Bench step aerobics group; CONTG: Control group; CI: Confidence interval; MD: Mean difference; ANCOVA: Analysis of covariance; WU: Wollega University; LSD: Least significant difference.

\section{Background}

Yoga is an ancient science of physical, mental and spiritual development. The word 'yoga' is derived from the roots of Sanskrit "Yuj' which means to join, to attach, to bind, yoke, and a concentrate or one attention. The literal meaning of the word 'Yoga' is 'yoke.' It is means of uniting the individual spirit with the universal spirit or God. It also relates with the experience of oneness or unity with inner being. It is a science by which the individual approaches to the truth. Yoga is ultimate for developing harmony among body, mind and spirit. Yoga asana are ways of moving and/or holding the body in different position $[1,2]$.

The great ancient Rishis, Vedas and Puranas also have given much importance to physical fitness [3]. Traditionally lord Shiva is regarded as the original founder of yoga. It is believed that this secret divine
Science of life, revealed to enlightened sages in meditation, was firstly narrated by lord Shiva to his wife Parvati for "Upliftment of humanity". Hiranyagarbha has been proclaimed as the very first teacher of yoga. Yoga asana has several exercises or postures that work wonders on fitness and health. It boosts physical strength, stamina and flexibility, improve blood circulation, enhance posture and muscle tone and bestow greater powers of concentration and self-control. Through the practice of yoga, we become aware of the connection between our emotional, mental and physical levels on the other hand pranayama is one of the five principles of Yoga or breathing and exercise which promote proper breathing [4-6].

${ }^{\star}$ Correspondence to: Ginenus Fekadu, Clinical Pharmacy unit, Department of Pharmacy, Institute of Health Sciences, Wollega University, P.O Box 395, Nekemte, Ethiopia. E-mail: take828pharm@gmail.com

Key words: asana yoga, bench step aerobics, pranayama yoga, physiological variables, yoga

Received: December 10, 2019; Accepted: December 17, 2019; Published: December 20, 2019 
Jabesa E (2019) Effect of selected yogic practice and bench step aerobics on improving selected physiological variables of females at Wollega University, Ethiopia: Randomized comparative trial

Yoga postures can lead to improvement in the sensitivity of the $\beta$-Cells of the pancreas to the glucose signal and improves insulin sensitivity due to enhancing cumulative effect of performing the postures. Pranayama practices stretches the lung tissue producing inhibitory signals from action of slowly adapting receptors and hyperpolarizing currents. These inhibitory signals coming from cardiorespiratory region involving vagi are believed to synchronize neural elements in the brain leading to changes in the autonomic nervous system. This condition is characterized by reduced metabolism and parasympathetic dominance $[7,8]$.

Aerobic exercise is a type of physical exercise helps to improve the way the cardiovascular system works. It makes the system more efficient in the absorption and transportation of oxygen. There are many different types of aerobic exercise and these exercises are done for extended periods at a moderate intensity level. The intensity should be between 60 to $85 \%$ of maximum heart rate. Aerobic exercise (also known as cardio) is physical exercise of relatively low intensity that depends primarily on the aerobic energy-generating process $[9,10]$.

Aerobic dance is a type of exercise that has many benefits for the body. It includes five dimensions: physical, social, emotional, intellectual, occupational and spiritual. The physical dimension of wellness includes developing cardiovascular endurance, muscular endurance, body composition, strength and flexibility. The social dimension is related to wellness which emphasizes common welfare of community, independence, as well as interdependence, with others and nature and pursuit of harmony within family. The emotional focuses on awareness and acceptance of your emotions and feelings. The intellectual dimension encourages creative, stimulation mental activities. The spiritual involves seeking meaning and purpose in human existence [11].

Regular practice of yoga and aerobics helps to keep body fit, controls cholesterol level, reduces weight, normalizes blood pressure and improves heart performance. According to the National Institutes of Health, when people actively seek to reduce the stress in their levels by quieting the mind, the body often works to heal itself. In this sense yoga and aerobic can be seen not only as a way to get into shape on several levels, but also as a tool for self-healing [12].

Today physical fitness of females is really questionable. Easily access of modern amenities restricts them to do hard physical labor. Gradually, they become sedentary. In their sedentary lives, physical inactivity leads to develop common metabolic disorders that may cause not only the morbidity and mortality, but also cause numerous health complications [13]. Efficacy of yoga practice and step aerobics as a safe fitness training module for Wollega University female has not been established yet. Hence, the present study was undertaken to assess the effect of yogic practice and bench step on selected physiological variables among female students at Wollega University.

\section{Methods}

\section{Study area and sampling techniques}

Wollega University (WU) is one of Ethiopian public higher educational institution established in 2007. The University is in Nekemte town, $332 \mathrm{~km}$ away from Addis Ababa. The university runs different programs including undergraduate and postgraduate programs [14]. sixty (60) subjects who were females age of 16-22 years, untrained to any of the yoga and step aerobics, free form deformities and ailments were included. With these 60 female subjects were selected using random sampling method.

\section{Study design}

Completely randomized comparative trial, consisting of a pre-test and post-test evaluation was employed.

\section{Study variables}

Respiratory rate, breath holding time and resting heart rate were dependent variables, whereas selected yogic practice (15 asana and 3 pranayama practice) and bench step aerobics training were independent variables.

\section{Administration of tests and training protocol}

Standard tests were conducted to measure the female's physiological capacity. To ensure the reliability of the data, test-retest method was used. A 10 weeks selected yogic practice and bench step aerobics program for three days per week approximately for 1 hour was conducted. The training program was administered in the afternoon session of the day. The control group was continued their regular program as usual. The study participants underwent their training program under continuous and strict supervision of the investigators and trainer.

\section{Statistical techniques and analysis of results}

Pretest and posttest data on the selected physiological variables were collected from the three study groups and analyzed using SPSS version 20 software package. Descriptive and analysis of covariance (ANCOVA) was conducted. The Least significant difference (LSD) post-hoc test was applied to determine the significant differences between the adjusted posttest means. In all cases the criterion for statistical significance was set at 0.05 level of confidence $(p<0.05)$. This study assessed the physiological variables of female subjects before and after the exercise training intervention. Physiological variables of the subjects were measured by using appropriate tools. The study discussed according to the factual data obtained.

\section{Operational and definition of terms}

- Yoga: is a psycho-somatic-spiritual discipline for achieving union and harmony between our mind, body, and soul and the ultimate union of our individual consciousness with the universal consciousness $[1,2,15]$.

- Asana: physical postures; third limb of Patanjal's eight-limbed path [16].

- Pranayama: Pranayama is derived from two Sanskrit words; namely prana, which means vital force or life energy, ayama means to prolong [16].

\section{Results}

The obtained $\mathrm{F}$ ratio value for pre-test mean was 0.064 which was less than the required value of 3.16 for significant at 0.05 level of confidence with the DF 2 and 57. This revealed that there was no significant difference between the groups at initial stage $(p=0938)$ (Table 1).

The obtained $\mathrm{F}$ ratio value for post-test mean was 13.48 which was greater than the expected value of 3.16 for significant at 0.05 level of confidence with the DF 2 and 57. This showed that the differences between the post-test means of the subject was significant.

The obtained $\mathrm{F}$ ratio value for adjusted test mean was 57.84 which was greater than the expected value of 3.16 for significant at 0.05 level of confidence with the DF 2 and 56 . The result of the study shows that 
Jabesa E (2019) Effect of selected yogic practice and bench step aerobics on improving selected physiological variables of females at Wollega University, Ethiopia: Randomized comparative trial

there was significant difference among the adjusted post-test mean of three groups on respiration rate. Hence, the adjusted post-test mean $\mathrm{F}$ ratio value was found to be statistically significant (Table 2).

In table 2 the mean difference of YP group and control group as well as BSAE and control groups were $5.512^{\star}$ and $5.200^{\star}$ respectively, which was greater than the confidence interval level of 0.000 at 0.05 level of confidence. The mean change made by the two experimental group $(\mathrm{MD}=.31<\mathrm{CI}=.590)$ showed no statistically significant difference. However, the mean changes made by the yoga practice and bench step aerobics groups were significantly greater than the control group. The result of the study indicated that selected yogic practice and bench step aerobics training significantly reduced the respiratory rate of the subjects than control group (Figure 1).

The obtained $\mathrm{F}$ ratio value for pre-test mean was 0.14 which was lesser than the required value of 3.16 for significant at 0.05 level of confidence with the DF 2 and 57. This revealed that there was no significant difference between the groups at initial stage. The obtained $\mathrm{F}$ ratio value for post-test mean was 43.30 which was greater than the required value of 3.16 for significant at 0.05 level of confidence with the DF 2 and 57. This showed that there was significant differences between the post-test means of the subjects (Table 3 ).
The obtained $\mathrm{F}$ ratio value for adjusted test mean was 87.57 was greater than the required value of 3.16 for significant at 0.05 level of confidence with the DF 2 and 56. There was significant difference among the adjusted post-test mean of three groups on breath holding time. Hence the adjusted post-test mean $\mathrm{F}$ ratio value was found to be statistically significant (Table 4).

Table 4 revealed that there were significant differences between the adjusted means of YP group and control group as well as BSAE group and control group with values of $9.674^{\star}$ and $9.589^{\star}$ respectively $(\mathrm{p}<0.001)$. There was no significant difference between the two experimental groups $(\mathrm{MD}=.085<\mathrm{CI}=.920)$. Selected yogic practice and bench step aerobics groups were found to be better significant in increasing the breath holding time of the subjects comparing with control group. The F-ratio ratio test applied to the pre-test means was 0.149 which was lesser than the required value of 3.16 for significant at 0.05 level of confidence with the DF 2 and 57.This proved that there was no significant difference between the groups at initial stage.

The obtained $\mathrm{F}$ ratio value for post-test mean was 17.24 which were greater than the required value of 3.16 for significant at 0.05 level of confidence. This proved that the differences between the post-test means of the subject was statistically significant (Table 5).

Table 1. Analysis of covariance for the pretest, posttest and adjusted posttest mean of the experimental and control groups on respiration rate (score in number of inhalations per one minute)

\begin{tabular}{|c|c|c|c|c|c|c|c|c|c|}
\hline \multirow{2}{*}{$\begin{array}{c}\text { Tests } \\
\text { Groups }\end{array}$} & \multicolumn{8}{|c|}{ Mean and Standard Deviation } & \multirow[b]{2}{*}{ Sig } \\
\hline & Yoga practice & $\begin{array}{c}\text { Bench step } \\
\text { aerobics }\end{array}$ & Control group & SoV & SS & Df & MSS & F-ratio & \\
\hline \multirow{3}{*}{ Pre } & \multirow{2}{*}{33.60} & \multirow{2}{*}{33.20} & \multirow{2}{*}{33.20} & A & 2.13 & 2 & 1.07 & \multirow{3}{*}{0.06} & \multirow{3}{*}{0.938} \\
\hline & & & & W & 947.20 & 57 & 16.62 & & \\
\hline & 3.98 & 3.91 & 4.32 & Total & 949.33 & 59 & & & \\
\hline \multirow{3}{*}{ Post } & 27.80 & 27.80 & 33.00 & A & 360.53 & 2 & 180.27 & \multirow{3}{*}{13.48} & \multirow{3}{*}{$<0.001$} \\
\hline & \multirow{2}{*}{3.04} & \multirow{2}{*}{3.78} & \multirow{2}{*}{4.08} & $\mathrm{~W}$ & 762.40 & 57 & 13.38 & & \\
\hline & & & & Total & 1122.93 & 59 & & & \\
\hline \multirow{2}{*}{$\begin{array}{l}\text { Adjusted } \\
\text { Post test }\end{array}$} & \multirow{2}{*}{27.60} & \multirow{2}{*}{27.90} & \multirow{2}{*}{33.10} & A & 383.22 & 2 & 191.61 & \multirow{2}{*}{57.84} & \multirow{2}{*}{$<0.001$} \\
\hline & & & & $\mathrm{W}$ & 185.52 & 56 & 3.31 & & \\
\hline
\end{tabular}

SoV-Source of variance, SS - sum of square, df-degree of freedom, MSS- mean sum of square, A=Among Means Variance, W=Within Group Variance, *Significant at 0.05 level of significance, $F=$ Ratio needed for significance at 0.05 level of significance $=d f(2,57)=3.16, d f(2,57)=3.16, d f(2,57)=3.16$

Table 2. The LSD post hoc test for the differences among the adjusted post-test paired means of the experimental and control group on respiration rate (score in number of inhales per min)

\begin{tabular}{|c|c|c|c|}
\hline Yoga practice & Bench step aerobics & Control group & $\begin{array}{c}\text { Mean } \\
\text { differences } \\
\text { interval value }\end{array}$ \\
\hline 27.592 & 27.904 & & .590 \\
\hline 27.592 & & 33.104 & .312 \\
\hline & 27.904 & 33.104 & $5.512^{*}$ \\
\hline
\end{tabular}

* Significant at 0.05 level of significance

Table 3: analysis of covariance for the pretest, posttest and adjusted posttest mean of the experimental and control groups on breath holding time (score in min)

\begin{tabular}{|c|c|c|c|c|c|c|c|c|c|}
\hline \multirow{2}{*}{$\begin{array}{c}\text { Tests } \\
\text { Groups }\end{array}$} & \multicolumn{8}{|c|}{ Mean \& Standard Deviation } & \multirow[b]{2}{*}{ Sig } \\
\hline & $\begin{array}{c}\text { Yoga } \\
\text { practice }\end{array}$ & $\begin{array}{l}\text { Bench } \\
\text { step } \\
\text { aerobics }\end{array}$ & $\begin{array}{l}\text { Control } \\
\text { group }\end{array}$ & SoV & SS & df & MSS & F-ratio & \\
\hline \multirow{3}{*}{ Pre } & \multirow{2}{*}{22.35} & \multirow{2}{*}{22.75} & \multirow{2}{*}{22.20} & $\mathrm{~A}$ & 3.23 & 2 & 1.62 & \multirow{3}{*}{0.14} & \multirow{3}{*}{0.872} \\
\hline & & & & W & 669.50 & 57 & 11.75 & & \\
\hline & 3.18 & 4.12 & 2.86 & Total & 672.73 & 59 & & & \\
\hline \multirow{3}{*}{ Post } & 32.05 & 32.30 & 22.25 & A & 1314.03 & 2 & 657.02 & \multirow{3}{*}{43.30} & \multirow{3}{*}{$<0.001$} \\
\hline & \multirow{2}{*}{4.24} & \multirow{2}{*}{4.17} & \multirow{2}{*}{3.20} & W & 864.90 & 57 & 15.17 & & \\
\hline & & & & Total & 2178.93 & 59 & & & \\
\hline \multirow{2}{*}{$\begin{array}{l}\text { Adjusted } \\
\text { Post test }\end{array}$} & \multirow{2}{*}{32.12} & \multirow{2}{*}{32.04} & \multirow{2}{*}{22.45} & A & 1234.03 & 2 & 617.01 & \multirow{2}{*}{87.57} & \multirow{2}{*}{$<0.001$} \\
\hline & & & & W & 394.57 & 56 & 7.046 & & \\
\hline
\end{tabular}

SoV- Source of variance, SS - sum of square, df- degree of freedom, MSS- mean sum of square, A=Among Means Variance, W=Within Group Variance, * Significant at 0.05 level of significance, $\mathrm{F}=$ Ratio needed for significance at 0.05 level of significance $=\mathrm{df}(2,57)=3.16$, $\mathrm{df}(2,57)=3.16$, $\mathrm{df}(2,57)=3.16$ 
Jabesa E (2019) Effect of selected yogic practice and bench step aerobics on improving selected physiological variables of females at Wollega University, Ethiopia:

Randomized comparative trial

Table 4. The LSD post hoc test for the difference between adjusted paired means of the experimental and control group on breath holding time (score in min)

\begin{tabular}{|c|c|c|c|}
\hline Yoga practice & Bench step aerobics & Control group & $\begin{array}{c}\text { Mean } \\
\text { differences }\end{array}$ \\
\hline 32.120 & 32.04 & & 0.09 \\
\hline 32.120 & & 22.45 & $9.67 *$ \\
\hline
\end{tabular}

* Significant at 0.05 level of confidence

Table 5. analysis of co-variance for pretest, posttest and adjusted posttest means of experimental and control groups on resting heart rate (score in beats per minute)

\begin{tabular}{|c|c|c|c|c|c|c|c|c|c|}
\hline Tests & Mear & nd Standard D & iation & & & & & & \\
\hline Groups & Yoga practice & $\begin{array}{c}\text { Bench } \\
\text { step aerobics }\end{array}$ & Control group & SoV & SS & df & MSS & F-ratio & Sig \\
\hline \multirow{3}{*}{ Pre } & \multirow{2}{*}{65.00} & \multirow{2}{*}{65.20} & \multirow{2}{*}{65.80} & A & 6.93 & 2 & 3.47 & \multirow{3}{*}{0.15} & \multirow{3}{*}{.862} \\
\hline & & & & $\mathrm{W}$ & 1326.40 & 57 & 23.27 & & \\
\hline & 5.17 & 4.87 & 4.40 & Total & 1333.33 & 59 & & & \\
\hline \multirow{3}{*}{ Post } & 58.80 & 56.80 & 65.50 & A & 830.53 & 2 & 415.27 & \multirow{3}{*}{17.24} & \multirow{3}{*}{$<0.001$} \\
\hline & \multirow{2}{*}{5.21} & \multirow{2}{*}{4.96} & \multirow{2}{*}{4.54} & W & 1373.40 & 57 & 24.10 & & \\
\hline & & & & Total & 2203.93 & 59 & & & \\
\hline \multirow{2}{*}{$\begin{array}{l}\text { Adjusted } \\
\text { post test }\end{array}$} & \multirow{2}{*}{59.10} & \multirow{2}{*}{56.92} & \multirow{2}{*}{65.08} & A & 711.42 & 2 & 355.71 & \multirow{2}{*}{65.45} & \multirow{2}{*}{$<0.001$} \\
\hline & & & & $\mathrm{W}$ & 304.34 & 56 & 5.44 & & \\
\hline
\end{tabular}

SoV- Source of variance, SS - sum of square, df- degree of freedom, MSS- mean sum of square, A=Among Means Variance, W=Within Group Variance, * Significant at 0.05 level of significance= Ratio needed for significance at 0.05 level of significance $=\operatorname{df}(2,57)=3.16$, df $(2,57)=3.16$, df $(2,57)=3.16$

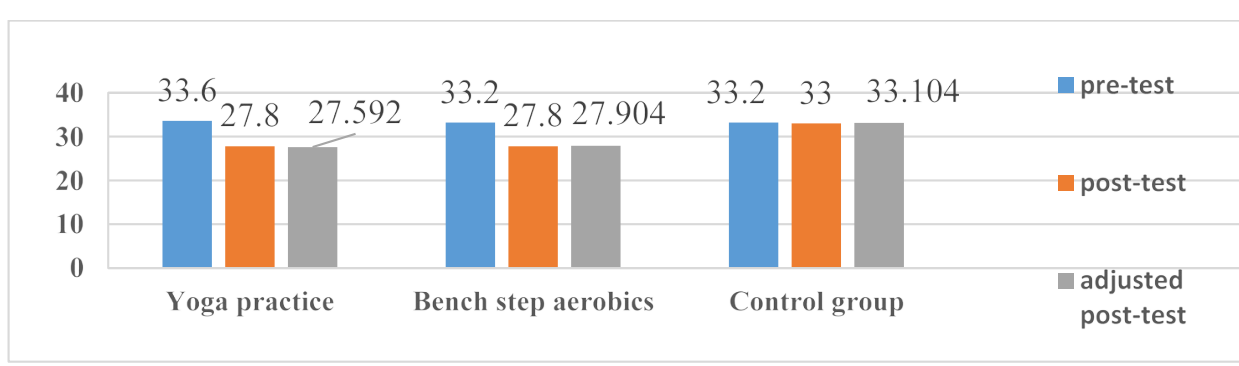

Figure 1. Mean comparison between the experimental and control groups on respiration rate

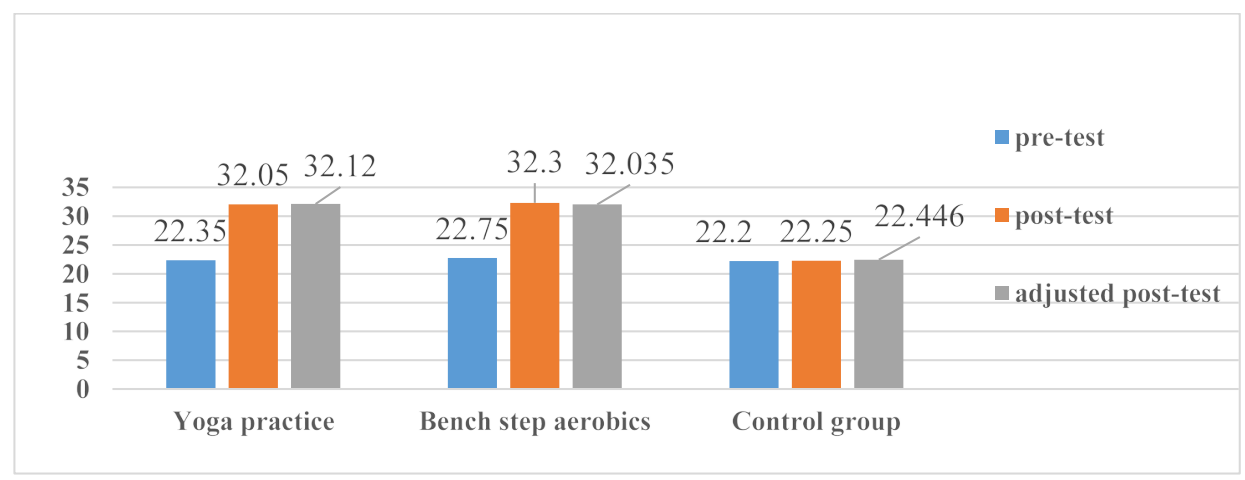

Figure 2. Graphical presentation of mean comparison between the experimental and control groups on breath holding time

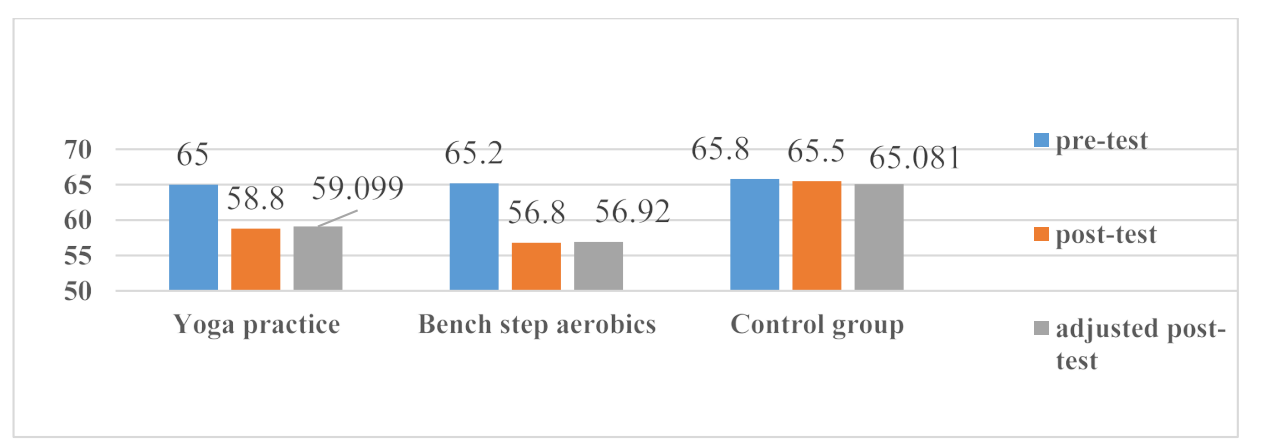

Figure 3. Graphical presentation of mean comparison between the experimental and control groups on resting heart rate 
Jabesa E (2019) Effect of selected yogic practice and bench step aerobics on improving selected physiological variables of females at Wollega University, Ethiopia: Randomized comparative trial

Table 6. The LSD post hoc test for the difference between adjusted paired means of the experimental and control group on resting heart rate (score in beats per minute)

\begin{tabular}{|c|c|c|c|c|}
\hline Yoga practice & $\begin{array}{c}\text { Bench step } \\
\text { aerobics }\end{array}$ & $\begin{array}{c}\text { Control } \\
\text { group }\end{array}$ & $\begin{array}{c}\text { Mean } \\
\text { differences }\end{array}$ \\
\hline 59.099 & 56.92 & & $2.18^{*}$ \\
\hline 59.099 & & 65.08 & .005 \\
\hline & 56.92 & 65.08 & $5.98^{*}$ \\
\hline
\end{tabular}

* Significant at 0.05 level of confidence

The obtained $\mathrm{F}$ ratio value for adjusted test mean was 65.45 was greater than the required value of 3.16 for significant at 0.05 level of confidence. This indicated that there was significant difference among the adjusted post-test mean of three groups on resting heart rate (Table $6)$.

The multiple mean comparisons shown in Table 6 showed that there were significant differences between the adjusted means of YP group and BSAE group, YP group and CONT group, BSAE group and CONT group, which was $2.18,5.98$ and 8.16 respectively. It indicated that resting heart rate was influenced by both training program. However, bench step aerobics training was found to be significantly better in decreasing resting heart rate of the subjects than selected yogic practice group and control group (Figure 3).

\section{Discussion}

The study revealed that the experimental group namely yoga practice group and bench step aerobics group had significantly improved respiration rate, resting heart rate and breath holding time of untrained female subjects after the 10 weeks of the training in contrast to control group.

The result of the study also revealed that the experimental group namely yoga practice group and bench step aerobics group had significantly decreased the respiration rate of the subjects after the 10 weeks of the training. It is also evident that the mean difference of YP group and CONT group, BSAE group and CONT groups was 5.51 and 5.20 respectively, which was greater than the confidence interval level of 0.00 at 0.05 level of confidence. The mean change made by the two experimental group $(\mathrm{MD}=0.312<\mathrm{CI}=.590)$ showed no statistically significant difference amongst the groups. However, the mean change made by the yoga practice and bench step aerobics group was significantly greater than the control group. The result of the study also indicated that selected yogic practice and bench step aerobics training significantly reduced the respiratory rate of the subjects than control group.

The major changes in the respiratory system from endurance training and pranayama or breathing exercise are an increase in the maximal rate of pulmonary ventilation, due to increases in both tidal volume and respiration rate, and an increase in pulmonary diffusion at maximal rates of work. This is primarily due to increases in pulmonary blood flow, particularly to the upper regions of the lung. The result of this study agreed with previous literatures [17-20].

There were positive effects on breath holding time due to 10 weeks selected yogic practice and bench step aerobics training. The study revealed that there weas significant differences between the adjusted means of YP group and CONT group, BSAE group and CONT group with values of 9.674 and 9.589 respectively, which was greater than the confidence interval level of 0.000 at 0.05 level of confidence. There was no significant difference between the two experimental groups ( $\mathrm{MD}=.085<\mathrm{CI}=.920$ ). The result of present study showed that selected yogic practice and bench step aerobics groups were found to be better in increasing the breath holding time of the subjects compared to control group. This may be due to the improvement in the efficiency of respiratory muscles which increase the tidal volume and increase the number, size and metabolic capacity of mitochondria to increase consumption of oxygen by the cells respectively. Heart rate and breathing rate will become slower while resting because of the increased efficiency of heart and lungs. It is possible to hold the breath longer because more oxygen is available to body with each breath. This study was comparable with previous articles [21-25].

The results of this study indicated that three times weekly selected yogic practice and bench step aerobics, for a period of 10 weeks can yield significant effects on resting heart rate of untrained female's subjects. There there were significant differences between the adjusted means of YP group and BSAE group, YP group and CONT group, BSAE and CONT group with values of $2.18,5.98$ and 8.16 respectively which was statically greater than the confidence interval level of 0.000 at 0.05 level of confidence. This result also indicated that resting heart rate was influenced by both training program. Here, bench step aerobics training was found to be significantly decreases resting heart rate of the subjects than selected yogic practice group and control group. These changes may be endurance training and yogic practice significantly influences how the autonomic nervous system controls heart function. It increases parasympathetic activity and decreases sympathetic activity in the human heart at rest. Endurance training-induced autonomic effects, coupled with a possible reduction in intrinsic heart rate, decrease resting heart rate. Long-term endurance training also decreases submaximal exercise heart rate by reducing sympathetic activity to the heart. The resting heart rate of those who exercise is also slower (both at rest and during exertions, will decrease) because less effort is needed to pump blood. The current finding was in compliance with a research conducted at different areas [26-30].

\section{Limitation of the study}

The study was associated with some limitations. First, no effort was Post to find out the effect of environmental changes during pre and post tests and the training period. However, dry weather prevailed mostly. Second, though the subjects were motivated verbally, no attempt was made to differentiate their motivation level during the testing and training period. Third, since the subjects were non-hostellers, the investigators did not take any effort to control and assess the quality and quantity of food taken by everyone. Finally, the quantum of physical exertion, lifestyle and physiological stress and other factors that affect the metabolic functions were also considered as limitation.

\section{Conclusion}

The findings of the study on physiological variables revealed that YP group and BSAE group showed significant superiority over the control group on reducing respiratory rate $(\mathrm{CI}: 0.00, \mathrm{p}<0.05)$. The mean change made by the two experimental group $(\mathrm{CI}=.590, \mathrm{p}>0.05)$ showed no statistically significant difference amongst the groups. YP group and BSAE group showed significant superiority over the control group on improving breath holding time $(\mathrm{CI}: 0.00, \mathrm{p}<0.05)$. The mean change made by the two experimental group $(\mathrm{CI}=.920, \mathrm{p}>0.05)$ showed no statistically significant difference amongst the groups. 
Jabesa E (2019) Effect of selected yogic practice and bench step aerobics on improving selected physiological variables of females at Wollega University, Ethiopia: Randomized comparative trial

YP group and BSAE group showed significant superiority over the control group on improving breath holding time (CI: $0.00, \mathrm{p}<0.05)$. Here, bench step aerobics training was found to be significantly better on decreasing resting heart rate of the subjects than yogic practice group $\left(\mathrm{MD}=2.18^{*}, \mathrm{p}<0.05\right)$. Over all, the result of the present study revealed that the experimental group namely, selected YPG and BSAEG had significantly improved Respiratory rate, breath holding time and resting heart rate of the subjects after the 10 weeks of training in contrast to control group.

\section{Acknowledgment}

We thank Wollega University for logistic support. We are grateful to study participants for their cooperation in the success of this study. The authors were also highly obliged to acknowledge those who helped to carried out this work directly or indirectly.

\section{Funding}

The study was funded by Wollega University. The funder had no role in study design, data collection and analysis, decision to publish or preparation of the manuscript.

\section{Availability of data and materials}

The datasets used and/or analyzed during the current study are available from the corresponding author on reasonable request.

\section{Authors' contributions}

EJ contributes in the design of the study, analysis and write up of the manuscript. MB made the data analysis, drafting, interpretation and edition of the data. GF contributed to the design of the study, monitoring the study and edition of the manuscript. All authors critically revised the manuscript and have approved the final manuscript.

\section{Ethics approval and consent to participate}

Ethical clearance was obtained from the Institutional Review Board (IRB) of Wollega University, College of computational and natural sciences. A written informed consent was obtained from the participants. All participants got the right to opt out of the research. This was done by explaining the objective and importance of the study as it would be beneficial for quality service delivery for future encounters. Neither the case records nor the data extracted was used for any other purpose. The confidentiality and privacy of participants were assured throughout by removing identifiers from data collection tools using different codes.

\section{References}

1. Kalidas Karak, Mrityunjoy Jana, Abhijit Manna (2015) Effect of yoga on anthropometrical and physiological variables of college going students. International Journal of Physical Education, Sports and Health 2: 245-249.

2. Amandeep Singh, Sukhdev Singh, Vishaw Gaurav (2011) Effects of 6-weeks yogasanas training on agility and muscular strength in sportsmen. International Journal of Educational Research and Technology 2: 72-74.

3. Uppal AK, Gautam GP (2000) Physical education and health. New Delhi: friends' publication

4. Johnbosco K (2018) Effect of Asanas on selected physical and physiological variables among young adult women. Asian Review of Social Sciences 7: 107-109.

5. Junkin SE, Kowalski K, Fleming T (2019) Yoga and self-esteem: Exploring change in middle-aged women.

6. Tandon OP (2012) Yoga and its applications. best and Taylor's physiological basis of medical practice. 12: 17-30.
7. Manjunatha S, Vempati RP, Ghosh D, Bijlani RL (2005) An investigation into the acute and long-term effects of selected yogic postures on fasting and postprandial glycemia and insulinemia in healthy young subjects. Indian J Physiol Pharmacol 49: 319-324. [Crossref]

8. Jerath R, Edry JW, Barnes VA, Jerath V (2006) Physiology of long pranayamic breathing: neural respiratory elements may provide a mechanism that explains how slow deep breathing shifts the autonomic nervous system. Med Hypotheses 67: 566571. [Crossref]

9. Plowman SA, Smith DL (2014) Exercise physiology for health, fitness, and performance. Philadelphia: Wolters Kluwer/Lippincott Williams \& Wilkins Health

10. McArdle WD, Katch FI, Katch VL (2006) Essentials of exercise physiology: lippincott williams \& wilkins.

11. (1998) American college of sports medicine position stand. The recommended quantity and quality of exercise for developing and maintaining cardiorespiratory and muscular fitness, and flexibility in healthy adults. Med Sci Sports Exerc. 30: 975-991.

12. Yokesh TP (2012) Effect of yogic practice and aerobic exercise on selected physical and physiological variables among overweight schoolboys. Elixir Soc. Sci 43: 6921-6923.

13. Usha Dnyanoba KodgirE (2013) Comparative effect of yoga and aerobic exercises on selected physiological variables of schoolgirls' golden research thoughts. 3: 1 .

14. Wollega University. http://www.wollegauniversity.edu.et/ Last Updated on 30 July 2019.

15. Madanmohan, Mahadevan SK, Balakrishnan S, Gopalakrishnan M, Prakash ES (2008) Effect of six weeks yoga training on weight loss following step test, respiratory pressures, handgrip strength and handgrip endurance in young healthy subjects. Indian J Physiol Pharmacol.; 52: 164-170. [Crossref]

16. Manjula Suri, Namita Saini, Shipra Gupta (2016) Exploring the physiological effects of yoga: a state-of-the-art review. International Journal of Physical Education, Sports and Health 3: 316-320.

17. Santoshi R. Saulkar (2015) Effect of yoga training on physiological variables of clerk working women. An International Peer Reviewed E-Journal of Multidisciplinary. 2 31-38.

18. Madanmohan, Thombre DP, Balakumar B, Nambinarayanan TK, Thakur S, et al (1992) Effect of yoga training on reaction time, respiratory endurance and muscular strength. Indian J Physiol Pharmacol 36: 229-233. [Crossref]

19. Madanmohan, Bhavanani AB, Dayanidy G, Sanjay Z, Basavaraddi IV (2012) Effect of yoga therapy on reaction time, biochemical parameters and wellness score of peri and post-menopausal diabetic patients. Int J Yoga 5: 10-15. [Crossref]

20. Madanmohan, Mahadevan SK, Balakrishnan S, Gopalakrishnan M, Prakash ES (2008) Effect of six weeks yoga training on weight loss following step test, respiratory pressures, handgrip strength and handgrip endurance in young healthy subjects. Indian J Physiol Pharmacol 52: 164-170. [Crossref]

21. Schell FJ, Allolio B, Schonecke OW (1994) Physiological and psychological effects of hatha-yoga exercise in healthy women. Int J Psychosom 41: 46-52. [Crossref]

22. Usha Rani K (2017) Effect of yogic exercise on selected physiological variables of working people. IOSR Journal of Humanities and Social Science (IOSR-JHSS) 22: 1-5.

23. Rajeswari M and Anbalagan (2017) Effects of varied combinations of aerobic dance, brain gym and yogasana on the selected psychological among schoolgirls. 4: 132-134.

24. Mukesh Kumar Mishra, Ajay Kumar Pandey, Shivendra Dubey (2015) Effect of eight weeks yogic training on selected physiological variables. International Journal of Physical Education, Sports and Health 1: 50-52.

25. Shelvam PV, Arunadevi S (2013) Effects of aqua aerobics and floor aerobics on breath holding time among schoolgirls. Voice of research 2: 2277-7733.

26. Sarojini Devi KSS, Usha Rani M (2013) Effect of yogic exercise and physical exercise on physical health and mental health. Journal of Evolution of Medical and Dental Sciences; 2: 3031-3039.

27. Lohan, Rajesh (2002) Effect of asanas and pranayamas on physical and physiological components of boys between age group 12-16 years. Journal of Adopted Physical Education and Yoga. 7: 47-55.

28. Reimers AK, Knapp G, Reimers C-D (2018) Effects of exercise on the resting heart rate: a systematic review and meta-analysis of interventional studies. J Clin Med 7 : 503. [Crossref] 
Jabesa E (2019) Effect of selected yogic practice and bench step aerobics on improving selected physiological variables of females at Wollega University, Ethiopia: Randomized comparative trial

29. Sawane MV, Gupta SS (2015) Resting heart rate variability after yogic training and swimming: A prospective randomized comparative trial. Int $J$ Yoga 8: 96-102. [Crossref]
30. Rayat Sunil (2015) Effect of yoga on selected physical and physiological variables of physical education students. IOSR Journal of Sports and Physical Education (IOSRJSPE) 2: 18-24.

Copyright: (O2019 Jabesa E. This is an open-access article distributed under the terms of the Creative Commons Attribution License, which permits unrestricted use, distribution, and reproduction in any medium, provided the original author and source are credited. 